\title{
Mango Fruit Collection by a Cuatrimotor Picker Avoids Fruit Fly Proliferation
}

\author{
Hahn $\mathrm{F}^{*}$ and Vargas CD \\ Department Agricultural Engineering, Chapingo Autonomous University, México \\ *Corresponding author: Hahn F, IAUIA, Department Agricultural Engineering, Chapingo Autonomous University, km 38.5 Carr. Mexico Texcoco, \\ Chapingo, México
}

Submission: 監 November 13, 2017; Published: 祭 March 12, 2018

\begin{abstract}
Mango (Mangifera indica L.) is one of the most marketable fruits worldwide. It requires special growth, harvest and postharvest treatments. Farms with hundreds of trees in production require of collecting the mangoes that fall to the soil before they rot. Those fruits also become the main infestation place of fruit fly larvae. This operation becomes very expensive without a four-wheel drive picker equipment. The developed implement picked one thousand fruits in two hours non-dependent on the fruit variety. The equipment employed during a harvest season eliminated fruit fly contamination. The equipment will produce new postharvest applications of mango fruits.
\end{abstract}

Keywords: Mango picker; Fruit fly infestation; Soil collection; Biodiversity; Eco-fertilizers

\section{Introduction}

Mango (Mangifera indica L.) is one of the most popular fruits grown throughout the tropics and subtropics, being highly desirable because of its delicious taste. The major mango producing countries are India, China, Mexico, Thailand, Indonesia, Pakistan, Nigeria, Philippines, Brazil, Egypt and Haiti [1]. Economic costs of mango postharvest losses are higher than field losses. The successful management of such diseases depend on the biological understanding of the pathological-system as well as the economics, efficiency and market tolerance of the control treatment. Nowadays, integrated disease management is the preferred strategy decreasing residual effects of chemical control [2]. The persistence of agrochemicals and in particular PBZ in the soil may result in contamination of nearby water bodies, thus presenting a possible hazard to human and animal health, and could also influence soil microbial activity with further effects on biodiversity [3]. A slight accumulation of PBZ in the soil over three years arose at harvest time. Application of single doses at the beginning of each crop year increased mango yields, without PBZ accumulation in the fruit [4]. This article shows a new machine that collects mango fruits in the soil during pre-harvest and harvesting periods. The built equipment is mounted to a tractor or a four-wheel drive cuatrimotor, lifting fruits automatically and avoiding mango rotting on the soil.

\section{Machine Development}

The current machine was developed to reduce fruit fly contamination on mango fruit previous harvesting. Fruit fly is one of the most serious pest of mango production sites affecting fresh fruit marketing. The female punctures the maturing fruits and lays eggs in small clusters inside the fruit. Contaminated fruits fall down and the maggots continue growing; fly maggots are seen in the damaged flesh. The equipment does not require any transmission and the wheels turn when the cuatrimotor is pulling it. The mangoes in the soil are picked-up by metallic fingers spaced 60 degrees along the one-meter cylindrical drum, (Figure 1). The fingers push-up the fruits of the soil and once at the top mangoes fall inside a hollow cylinder, (Figure 2). Once the cylinder is full, fruits are taken to a determined place where they are removed for further processing. This equipment allows taking operative decisions for fruit processing as biogas production, pulp drying and pectin extraction. In addition, eco-fertilizers are produced. The machine collected 1000 fruits in two hours. The implement can be used in front or in the back of the cuatrimotor with similar results. Cuatrimotor speed is not a parameter that affects its performance. The equipment was tested with mangoes of different varieties and the cylinder gets full with:
a) 80 Kent var. mango,
b) 110 Ataulfo var. mango,
c) 100 Alphonso var. mango.

The use of this implement avoids fruit fly larvae proliferation on soil rot mango fruits, decreasing tree mango contamination drastically during the next season. A farm that did not collected mango fruits of the soil, presented fruit fly larvae in half of the harvested fruit. Ten workers are needed to collect manually the fruits that the picker grabs automatically, avoiding harvest losses. 
A single worker can pick manually fifteen fruits per minute without moving laterally; after one hour requires rest to avoid back-pain. If the worker moves sideways only 10 mangoes are picked in one minute (600 fruits/hour). The main drawback of manual collection is that a plastic tank of twenty-liter can only store 15 mangoes.
Bees and wasps sting workers causing them to miss work days. Assistance studies along two months, showed that workers missed ten days due to bee and wasp sting. Many plastic tanks are required and its movement to the discharging place will take a longer time than the collecting time.

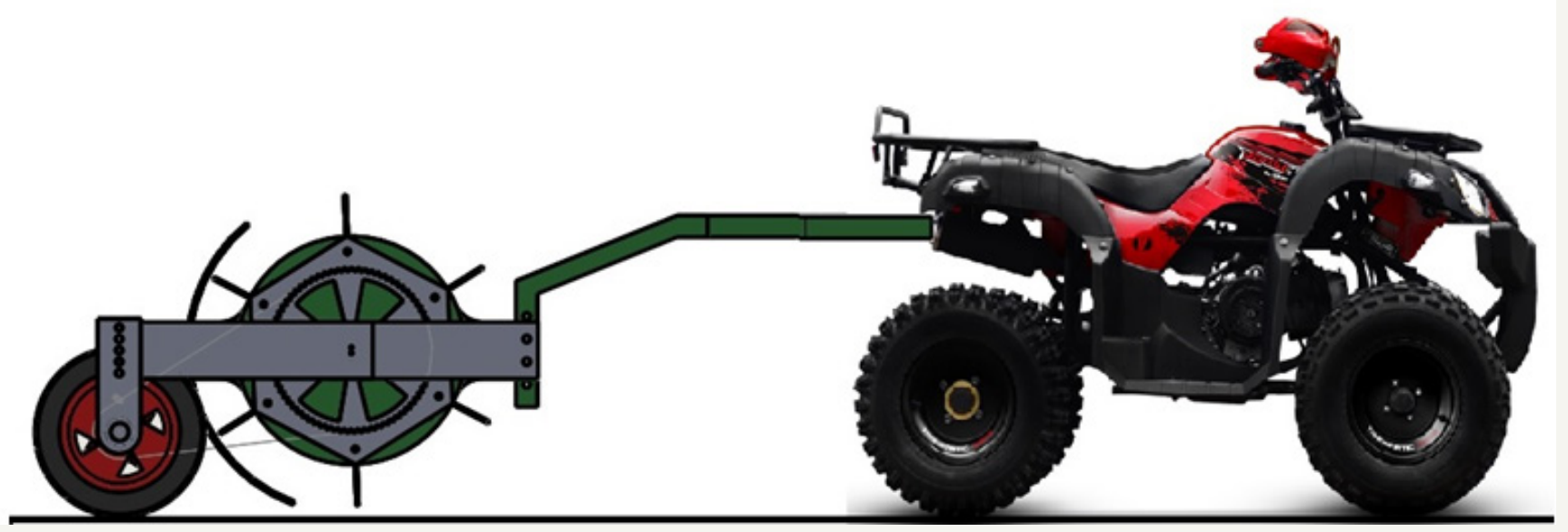

Figure 1: Theoretical image of the fruit picker.
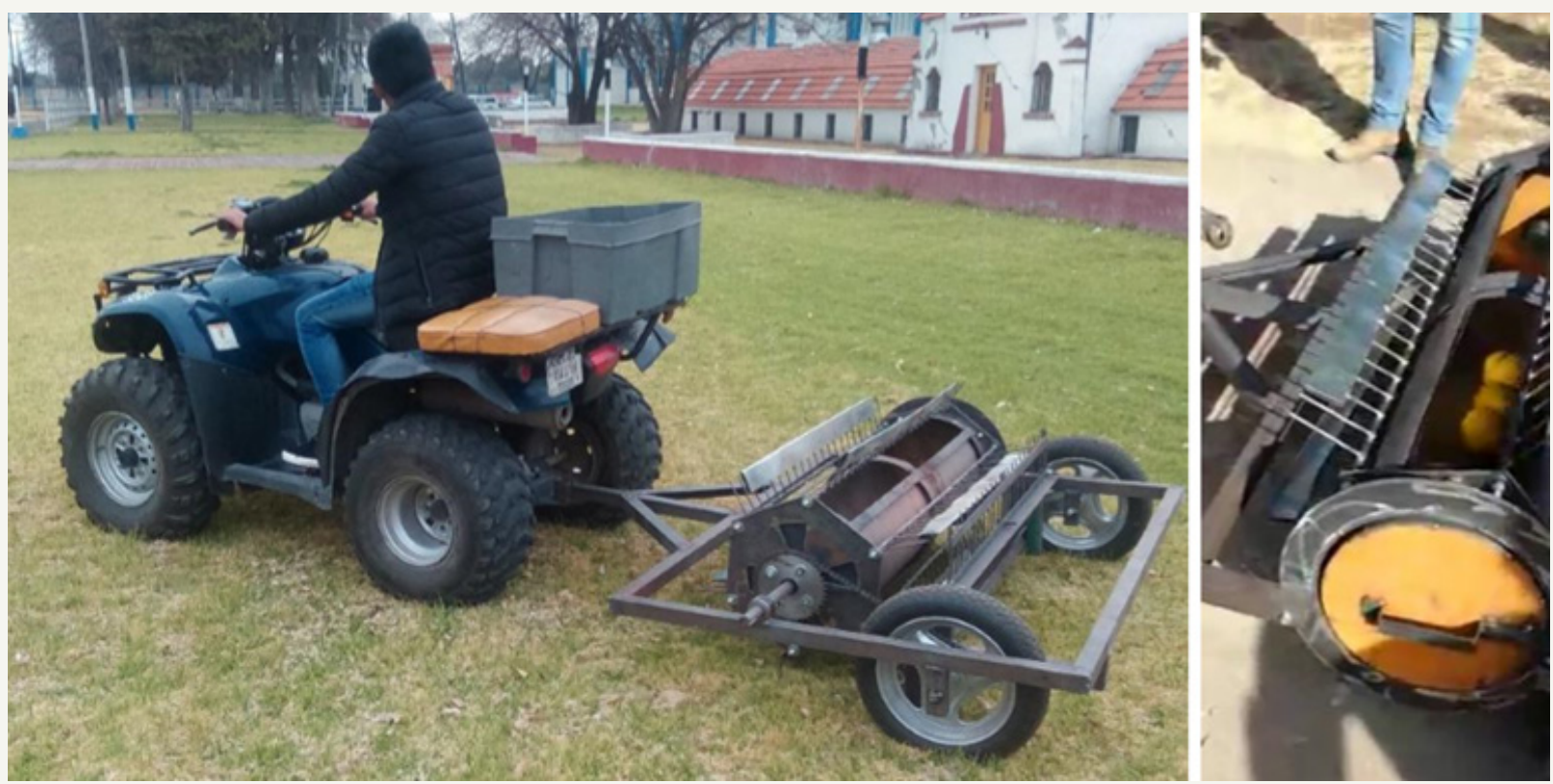

Figure 2: Fruit picker in the back of the cuatrimotor showing some fruits inside the cylinder.

\section{References}

1. Swart G (2010) Epidemiology and control of important post-harvest diseases in mangoes in South Africa. Southern African Society for Plant Pathology, Midland, South Africa.

2. Alemu K (2014) Dynamics and management of major postharvest fungal diseases of mango fruits. Journal of Biology, Agriculture and Healthcare 4(27): $14-21$
3. Neidhart S, Jaradrattanapaiboon A, Reintjes K, Jöns B, Leitenberger, et al. (2006) Which risks do result from the application of paclobutrazol in off-season mango production regarding residues in fruit and soil? First results of a long-term field study in northern Thailand. In: Towards sustainable livelihoods and ecosystems in mountainous regions, Chiang Mai, Thailand.

4. Sharma D, Awasthi MD (2005) Uptake of soil applied paclobutrazol in mango (Mangifera indica L.) and its persistence in fruit and soil. Chemosphere 60(2): 164-169. 
(c) Creative Commons Attribution 4.0

For possible submissions Click Here Submit Article

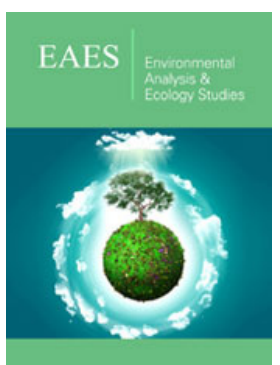

Environmental Analysis \& Ecology Studies

\section{Benefits of Publishing with us}

- High-level peer review and editorial services

- Freely accessible online immediately upon publication

- Authors retain the copyright to their work

- Licensing it under a Creative Commons license

- Visibility through different online platforms 